\title{
Septal myectomy after failed alcohol ablation: Does previous percutaneous intervention compromise outcomes of myectomy?
}

\author{
Eduard Quintana, MD, FETCS, ${ }^{\text {a,b }}$ Anna Sabate-Rotes, MD, PhD, ${ }^{c}$ Joseph J. Maleszewski, MD,, d \\ Steve R. Ommen, MD, ${ }^{\mathrm{c}}$ Rick A. Nishimura, MD, ${ }^{\mathrm{c}}$ Joseph A. Dearani, MD, ${ }^{\mathrm{a}}$ and Hartzell V. Schaff, $\mathrm{MD}^{\mathrm{a}}$
}

\section{ABSTRACT}

Objective: The impact of prior alcohol septal ablation in patients who require septal myectomy for hypertrophic obstructive cardiomyopathy is unknown.

Methods: Thirty-one patients with unsuccessful alcohol septal ablation who underwent septal myectomy were matched 1:2 to patients having had a myectomy as the only invasive procedure for hypertrophic obstructive cardiomyopathy. Study outcomes were cardiac death, advanced heart failure, and appropriate implantable cardioverter defibrillator discharge. The results of surgery, echocardiograms, and pathology specimens were compared between groups.

Results: Patients with previous alcohol septal ablation had increased diastolic dysfunction in preoperative echocardiography, as well as more implantable cardioverter defibrillators implanted $(32 \%$ vs $11 \%, P=.01)$, more arrhythmias in preoperative Holter monitoring ( $43 \%$ vs $13 \%, P=.02)$, and a higher incidence of postoperative complete heart block $(19.4 \%$ vs $1.6 \%, P<.01)$. Two patients died early postoperatively in the prior alcohol septal ablation group, and no patients died in the primary myectomy group. One patient in each group had an implantable cardioverter defibrillator $(P=.52)$. At a mean follow-up of 3.2 years, 7 of 31 patients and 6 of 62 patients progressed to advanced heart failure in the prior alcohol septal ablation group and the primary myectomy group, respectively $(P=.1)$ Histopathologic analysis demonstrated greater interstitial ( $70 \%$ vs $26 \%$, $P<.01)$ and endocardial fibrosis $(87 \%$ vs $67 \%, P=.04)$ in the alcohol septal ablation group.

Conclusions: Patients with prior alcohol septal ablation undergoing surgical septal myectomy may have an increased risk of cardiac death, advanced heart failure, and implantable cardioverter defibrillator discharges. This supports septal myectomy as the preferred treatment for septal reduction therapy, avoiding scarring and diastolic dysfunction inherent to alcohol septal ablation. (J Thorac Cardiovasc Surg 2015;150:159-67)

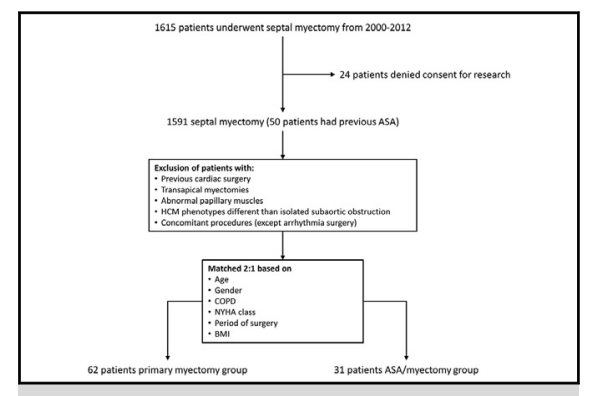

Flowchart of studied patients.

\section{Central Message}

Previous failed alcohol septal ablation compromises the outcomes of septal myectomy. Patients may have increased risk of sudden death, heart failure, and arrhythmias. This supports septal myectomy as the preferrec treatment for septal reduction therapy, avoiding scarring and diastolic dysfunction inherent to alcohol septa ablation.

\section{Perspective}

Despite the uncertainties on the long-term impact of septal alcohol ablation, this technique is widely performed. A proportion of this population may require a rescue septal myectomy to relieve persistent obstruction. This study explores the possible impact of alcohol ablation on patient requiring septal myectomy. The results show an increased risk of perioperative death, advanced heart failure, and implantable cardioverter defibrillator (ICD) discharges in comparison with patients having septal myectomy as the primary septal reduction therapy. Our data contribute to accumulating evidence that the infarction induced by alcohol septal ablation may have adverse and unexpected consequences.

See Editorial Commentary page 167

\footnotetext{
From the ${ }^{\mathrm{a} D i v i s i o n}$ of Cardiovascular Surgery, Mayo Clinic, Rochester Minn; ${ }^{\mathrm{b}}$ Servei de Cirurgia Cardiovascular, Hospital Clínic de Barcelona, Universitat de Barcelona, Barcelona, Spain; ' Division of Cardiovascular Diseases, Mayo Clinic, Rochester, Minn; and ${ }^{\mathrm{d}}$ Division of Anatomic Pathology, Mayo Clinic, Rochester, Minn. AS-R was supported by Fundació La Caixa, Barcelona, Spain.

Received for publication Jan 3, 2015; revisions received March 18, 2015; accepted for publication March 26, 2015; available ahead of print May 1, 2015.
}

\footnotetext{
Address for reprints: Hartzell V. Schaff, MD, Division of Cardiovascular Surgery, Mayo Clinic College of Medicine, 200 First St SW, Rochester, MN 55905 (E-mail: schaff@mayo.edu). $0022-5223 / \$ 36.00$

Copyright $(2015$ by The American Association for Thoracic Surgery http://dx.doi.org/10.1016/j.jtcvs.2015.03.044
} 


$$
\begin{aligned}
& \text { Abbreviations and Acronyms } \\
& \text { CI }=\text { confidence interval } \\
& \text { HCM }=\text { hypertrophic cardiomyopathy } \\
& \text { ICD }=\text { implantable cardioverter defibrillator } \\
& \text { LVOT }=\text { left ventricular outflow tract } \\
& \text { NSVT }=\text { nonsustained ventricular tachycardia } \\
& \text { SD }=\text { sudden death } \\
& \text { VT }=\text { ventricular tachycardia }
\end{aligned}
$$

Supplemental material is available online.

In hypertrophic cardiomyopathy (HCM), left ventricular outflow tract (LVOT) obstruction is responsible for disabling symptoms in a large proportion of patients ${ }^{1,2}$ and confers a worse prognosis. ${ }^{3}$ Relief of LVOT obstruction by transaortic septal myectomy is a safe procedure that restores functional capacity and quality of life in symptomatic patients, and late survival of surgical patients is similar to that of the general matched population. ${ }^{4,5}$ Many experts consider transaortic septal myectomy to be the gold standard for septal reduction therapy. ${ }^{6}$

Alcohol septal ablation has emerged as an alternative to septal myectomy. ${ }^{7}$ Although alcohol septal ablation is performed percutaneously, the procedural risks of death and morbidity are not lower than the risks of operation. ${ }^{8}$ In many countries, alcohol septal ablation is performed exclusively for septal reduction in patients with obstructive HCM. ${ }^{9}$

There are distinct differences in the mechanism of relief of LVOT obstruction with alcohol septal ablation compared with surgical myectomy. In alcohol septal ablation, injection of ethanol creates a myocardial infarction associated with significantly higher early complications than septal myectomy. ${ }^{10,11}$ Overall hemodynamic success after alcohol septal ablation is reported to be $70 \%$, with an approximate $20 \%$ incidence of recurrence of severe symptoms. ${ }^{12}$ Thus, a sizeable proportion of patients receiving alcohol septal ablation may require transaortic septal myectomy for the relief of LVOT obstruction, and the outcome of such patients may be impaired. ${ }^{13,14}$

In the present study, we sought to determine whether failed alcohol septal ablation compromises the early and midterm outcomes of patients requiring septal myectomy. For a better understanding of differences in outcome, we evaluated diastolic function by strain echocardiography and reviewed grades of septal scarring on histologic specimens.

\section{MATERIALS AND METHODS Study Population}

The study included patients with subaortic dynamic LVOT obstruction who underwent septal myectomy from January 2000 to July 2012. Patients with previous alcohol septal ablation and myectomy were matched to patients who had a transaortic septal myectomy without prior ablation (Figure 1). Finally, 31 cases and 62 controls were included for the comparison. Twenty-eight patients had 1 previous alcohol septal ablation, and 3 patients had several percutaneous procedures. Twelve patients previously underwent alcohol septal ablation at our institution, and 19 patients underwent septal ablation elsewhere. This clinical study was approved by the Mayo Clinic College of Medicine Institutional Review Board, and patients agreed to research authorization.

\section{Diagnostic Evaluation}

HCM was defined as a hypertrophic and nondilated left ventricle in the absence of other cardiac or systemic disease that could explain such hypertrophy. ${ }^{15}$ Indications for surgery were symptoms refractory to medical treatment and LVOT gradient $50 \mathrm{~mm} \mathrm{Hg}$ or greater at rest or provocation. Echocardiographic studies were performed at baseline according to guidelines. ${ }^{1}$ Invasive monitoring was used to elucidate gradients when obstruction was latent. ${ }^{16,17}$

\section{Previous Alcohol Septal Ablation}

In our practice, patients were counseled about both surgical and percutaneous options with recommendations for surgical myectomy in most patients who had anticipated low operative risk and recommendation for alcohol septal ablation for elderly patients and those with important comorbid conditions. ${ }^{10,11}$ Technical details regarding our institutional approach to percutaneous alcohol septal ablation have been described. ${ }^{18}$

\section{Surgical Procedure}

Operations were performed through median sternotomy, cardiopulmonary bypass, and blood cardioplegia for myocardial protection. Through an aortotomy, the point of obstruction was identified and extended septal myectomy was performed with a scalpel blade. The initial incision in the septum was made upward and then leftward over to the anterior leaflet of the mitral valve. The area of septal excision was then deepened and lengthened toward the apex of the heart. ${ }^{19}$ To confirm complete relief of the LVOT obstruction, we used intraoperative echocardiography and routinely measured simultaneous aortic and left ventricular pressure by direct needle puncture after myectomy. ${ }^{20}$

In cases of previous ablation, gross findings at operation were variable. Endocardial scar was present in all patients, but surrounding infarcted myocardium was not always visible. The gritty texture of the septum was characteristic with scar tissue mixed with muscle. The extent of infarcted myocardium was difficult to assess at the time of surgery.

\section{Strain Analysis}

Images from preoperative echocardiograms were analyzed with Velocity Vector Imaging software (VVI Siemens Medical Systems, Mountain View, Calif) by a single observer (AS-R) blinded to the clinical data. A total of 16 segments from the apical 4-chamber, long-axis, and 2-chamber views were used for assessing global longitudinal left ventricular systolic strain, strain rate, and early diastolic strain rate. Septal segments of the apical 4chamber and long-axis views were used for assessing septal systolic strain, strain rate, and early diastolic strain rate. A total of 79 of 93 patients were available for analysis $(85 \%)$.

\section{Histopathologic Analysis}

Tissue slides from the study patients were retrieved from the Mayo Clinic Tissue Registry. Slides were prepared from routine diagnostic sampling of 
1615 patients underwent septal myectomy from 2000-2012

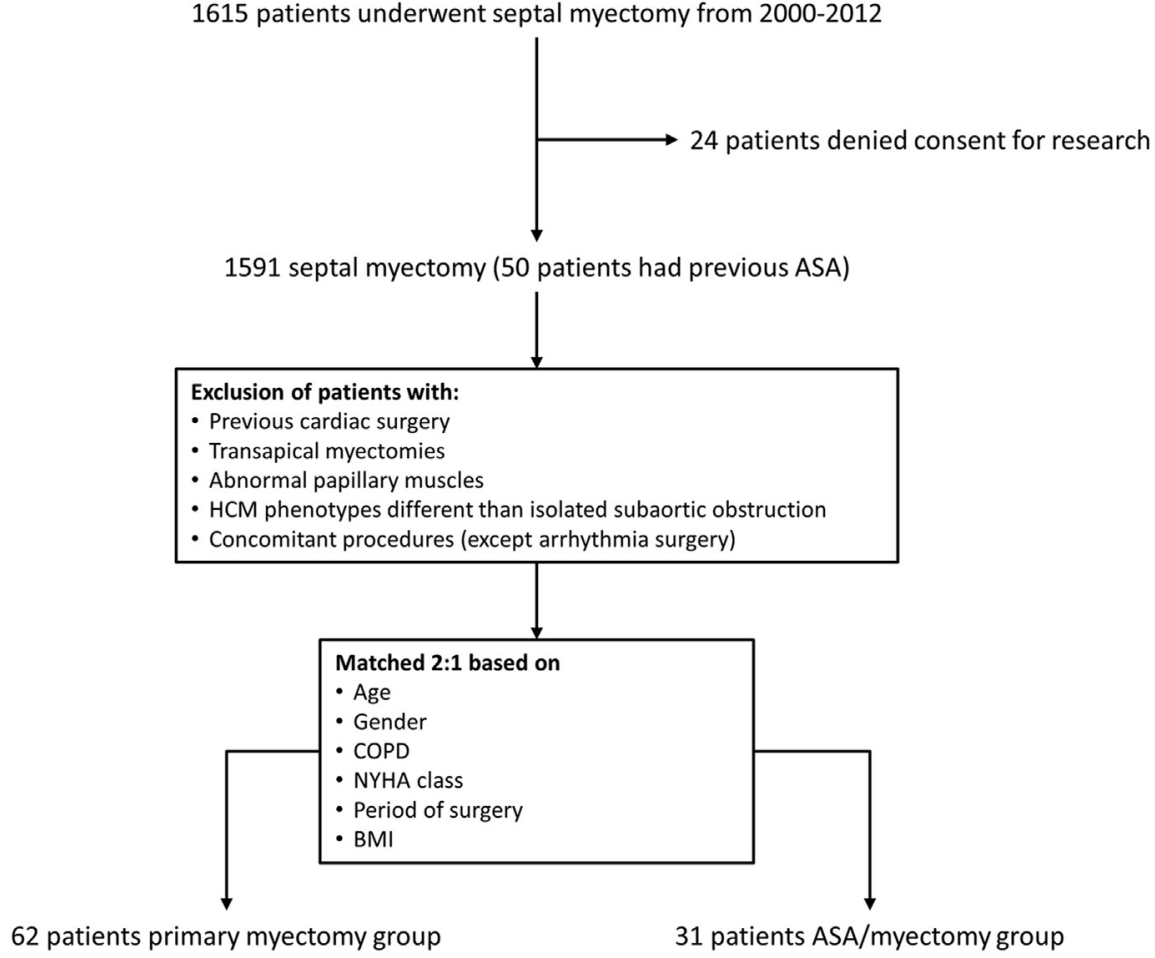

FIGURE 1. Flowchart of studied patients. ASA, Alcohol septal ablation; $H C M$, hypertrophic cardiomyopathy; COPD, chronic obstructive pulmonary disease; NYHA, New York Heart Association; BMI, body mass index.

the specimen at the time of surgery. Hematoxylin-eosin-stained slides were reviewed retrospectively by a single cardiovascular pathologist (JJM) blinded to clinical data for the following parameters: myocyte hypertrophy, myocyte disarray, endocardial fibrosis, myocyte vacuolization, myocardial infarction, inflammation, amyloidosis, and calcification.

Hypertrophy was assessed by longitudinally sectioned myocyte diameter and graded as mild if the diameters were consistently $20 \pm 4 \mu \mathrm{m}$, moderate if the diameters were consistently $29 \pm 4 \mu \mathrm{m}$, or marked if the diameters were consistently $38 \pm 4 \mu \mathrm{m}$. Myocyte disarray included cellular interlacing, whirling, or herringbone pattern ${ }^{21}$ and was semiquantitatively assessed as absent, mild, moderate, or severe on the basis of the extent of tissue involvement.

The endocardium was evaluated for fibrotic thickening as mild, moderate, or marked on the basis of the most thickened area (Figure 2, A). Likewise, interstitial fibrosis was assessed and described semiquantitatively as mild, moderate, or marked on the basis of the overall amount of interstitial fibrosis in the sampled myocardium (Figure 2, B).

\section{Follow-up}

Patient follow-up was complete and averaged $3.2 \pm 2.7$ years (maximum of 11.3 years). Follow-up data were derived from medical charts or written correspondence from referring physicians and patients. Additional questionnaires were sent to patients and families 1, 3, 5, and 10 years postoperatively. Vital status assessment was supplemented with the aid of the Social Security Death Index and confirmed by review of charts and surveys. Autopsy reports and death certificates were requested and reviewed when available.

\section{Implantable Cardioverter Defibrillators}

Implantations of ICDs were performed at the recommendation of referring cardiologists in accordance with established guidelines. ${ }^{1,22}$ Device interrogation was performed at our clinic or performed locally and supervised by referring cardiologists at regular intervals or when patients had symptoms. Appropriate discharges were those that terminated ventricular fibrillation or ventricular tachycardia (VT) and successful antitachycardia pacing bursts.

\section{Statistical Analysis}

Patients who underwent alcohol septal ablation and subsequent myectomy were matched by propensity score to patients who underwent myectomy as the primary treatment. The calipers used were \pm 0.15 $(0.25 \times$ standard deviation of $\log$ of propensity scores $)$ for the probability of prior alcohol septal ablation. For each case, 2 control subjects were randomly selected from the potential pool of controls defined by the calipers. The propensity for prior alcohol septal ablation was estimated using a logistic regression model with the response variable being prior alcohol septal ablation (yes/no) and the independent variables being surgery date (range, 5 years), age, gender, body mass index, preoperative creatinine level, New York Heart Association class, and chronic obstructive pulmonary disease.

Data were analyzed with SAS, version 9 (SAS Institute Inc, Cary, NC). Descriptive statistics for categoric variables are reported as frequency and percentage, and continuous variables are reported as mean (standard deviation) or median (range) as appropriate. Categoric variables were compared between cases and controls using the chi-square test or Fisher exact test, and continuous variables were compared using the 2-sample $t$ test or Wilcoxon rank-sum test where appropriate.

The Kaplan-Meier method was used to draw survival curves and calculate 5-year survival statistics for long-term outcomes. All statistical tests were 2 -sided with the alpha level set at 0.05 for statistical significance.

\section{Study End Points}

Our primary end points were cardiac death, advanced heart failure, and appropriate ICD therapy at follow-up. Cardiac death was defined as a death 


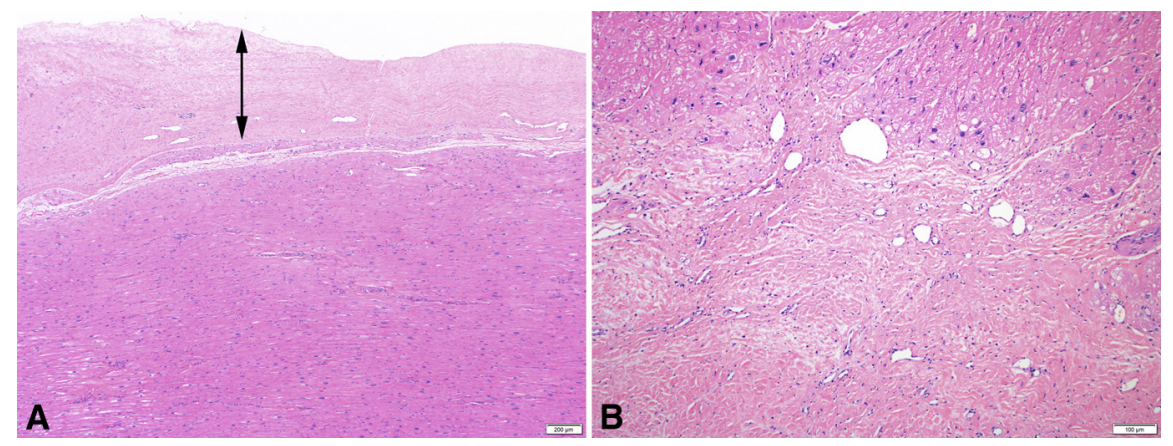

FIGURE 2. A, Photomicrograph exhibiting moderate endocardial thickening (arrowed line) (hematoxylin-eosin staining; original magnification $\times 40$ ). B, Photomicrograph showing interstitial (replacement-type) fibrosis (bottom) with pericellular-type fibrosis extending outward in between the myocytes (top). Marked myocyte hypertrophy with karyomegaly is also apparent (hematoxylin-eosin; original magnification $\times 100$ ).

resulting from heart failure or sudden cardiac death in patients who had an abrupt loss of consciousness within 1 hour of acute symptoms, and the cause of death could not be attributed to other processes in the postmortem examination. Classification of advanced heart failure was based on the presence of symptoms equivalent to New York Heart Association class III or IV despite maximal medical therapy.

\section{RESULTS}

\section{Baseline Patient Characteristics}

There were a total of 93 patients ( $43 \%$ were female) included in this study, and the mean age at the time of myectomy was $57 \pm 13$ years. Table 1 presents the baseline characteristics of all patients. All patients were under appropriate medical treatment consisting of beta-blockers or calcium channel blockers or both according to clinical tolerance; there were no differences in therapeutic regimen.

\section{Primary End Points}

There were no differences in follow-up times between the groups $(P=.41)$. During a mean follow-up of $3.2 \pm 2.7$ years (maximum of 11.3 years), there were 4 all-cause deaths in 31 patients $(13 \%)$ in the prior alcohol septal ablation group and 4 deaths in 62 patients $(6.5 \%)$ in the primary myectomy group. Kaplan-Meier estimates of survival at 1 year were $97.8 \%$ (95\% confidence interval [CI], 93.6$100)$ in the primary myectomy group and $92 \%(95 \% \mathrm{CI}$, 82.8-100) in the prior alcohol septal ablation group $(P=.20)$. During the same interval of time, there were 2 cardiac deaths $(6.5 \%)$ in the prior alcohol septal ablation group and none in the primary myectomy group. Beyond this first year, we did not observe mortality.

During the follow-up, 7 patients progressed to advanced degrees of heart failure in the prior alcohol septal ablation group and 6 patients progressed to advanced degrees of heart failure in the primary myectomy group $(P=.1)$. Freedom from this event was $96.3 \%$ (95\% CI, 89.4-100), $89.8 \%$ (95\% CI, 77-100), and $89.8 \%$ (95\% CI, 77-100) at 1, 3, and 5 years follow-up, respectively, in the prior alcohol septal ablation group. Freedom from this event was 100\% (95\% CI, 100-100), 97.6\% (95\% CI, 93.1-100), and
94.1\% (95\% CI, 86.4-100) at 1, 3, and 5 years follow-up, respectively, in the primary myectomy group.

During the same period, 1 patient in each group had an ICD firing, and this occurred during the first year after surgery. Freedom from ICD therapies was $94.4 \%(95 \%$ CI, 84.4-100) in the prior alcohol septal ablation group and $97.6 \%$ (95\% CI, 93.1-100) in the primary myectomy group at 1,3 , and 5 years follow-up $(P=.52)$.

\section{Early and Late Survival}

There were 2 early deaths in the prior alcohol septal ablation group, and 1 of these occurred in the hospital. The first patient underwent successful septal myectomy without detectable LVOT gradient after surgery but had persistent low cardiac output due to diastolic dysfunction, and the patient died. The second patient was a 39-year-old man who had a prior alcohol septal ablation and died suddenly at home 3 weeks postoperatively. At postmortem examination, no anatomic cause of death was found, and death was attributed to arrhythmia. During follow-up, there were 2 deaths related to cancer in the prior alcohol septal ablation group. In the primary myectomy group, there were no early deaths, but 4 late noncardiac deaths.

\section{Pacing and Rhythm}

After surgery, the incidence of complete heart block defined as new and persistent third-degree atrioventricular block (at last available electrocardiogram or last device interrogation with underlying rhythm analysis) was higher in the prior alcohol septal ablation group at $19.4 \%$ compared with $1.6 \%$ in the primary myectomy group $(P<.01)$ (Table 2$)$. Of note, 2 patients in the primary myectomy group received a pacemaker early after surgery but had normal sinus rhythm at last follow-up. In the prior alcohol septal ablation group, the incidence of events triggering ICD therapies was $3.2 \%$ compared with $1.6 \%$ in the primary myectomy group. The patient in the prior alcohol septal ablation group who had ICD discharge (ventricular fibrillation 4 months after surgery) had VT/nonsustained ventricular tachycardia (NSVT) on his 
TABLE 1. Preoperative baseline characteristics

\begin{tabular}{|c|c|c|c|c|c|}
\hline \multirow[b]{2}{*}{ Variable } & \multicolumn{2}{|c|}{ Prior alcohol septal ablation } & \multicolumn{2}{|c|}{ Primary myectomy } & \multirow[b]{2}{*}{$P$ valu } \\
\hline & $\mathbf{n}$ & Value & $\mathbf{n}$ & Value & \\
\hline Age & 31 & $57 \pm 13$ & 62 & $57 \pm 13$ & 1.00 \\
\hline Female & 31 & $14(45)$ & 62 & $26(42)$ & .77 \\
\hline BMI & 31 & $32 \pm 6$ & 62 & $32 \pm 5$ & 1.00 \\
\hline Hypertension & 31 & $17(55)$ & 62 & $22(36)$ & .07 \\
\hline Diabetes & 31 & $3(10)$ & 62 & $8(13)$ & .65 \\
\hline Previous CVA & 31 & $2(6)$ & 62 & $4(6)$ & 1.00 \\
\hline COPD & 31 & $4(13)$ & 62 & $10(16)$ & .68 \\
\hline Atrial fibrillation & 31 & $2(7)$ & 62 & $3(5)$ & .72 \\
\hline Creatinine $(\mathrm{mg} / \mathrm{dL})$ & 31 & $1 \pm 0.2$ & 62 & $1 \pm 0.2$ & .95 \\
\hline \multicolumn{6}{|l|}{ Symptoms } \\
\hline Dyspnea & 31 & $31(100)$ & 62 & $62(100)$ & 1.00 \\
\hline NYHA (III/IV) & 31 & $27(87)$ & 62 & $54(87)$ & 1.00 \\
\hline Exercise test (FAC) & 10 & $68 \pm 11$ & 24 & $61 \pm 15$ & .15 \\
\hline Angina & 31 & $14(45)$ & 62 & $28(45)$ & 1.00 \\
\hline Syncope/presyncope & 31 & $11(35)$ & 62 & $19(31)$ & .63 \\
\hline SD & 31 & 0 & 62 & 0 & - \\
\hline Family obstructive HCM & 31 & $9(29)$ & 62 & $13(21)$ & .39 \\
\hline Familial SD & 31 & $5(16)$ & 62 & $10(16)$ & 1.00 \\
\hline Preoperative complete heart block & 31 & $4(13)$ & 62 & 0 & $<.01$ \\
\hline Preoperative ICD implanted & 31 & $10(32)$ & 62 & $7(11)$ & .01 \\
\hline ICD discharge before myectomy & 31 & $3(10)$ & 62 & $2(3)$ & .19 \\
\hline Preoperative Holter NSVT/VT & 14 & $6(43)$ & 32 & $4(13)$ & .02 \\
\hline MRI delayed enhancement & 16 & $12(75)$ & 35 & $19(54)$ & .20 \\
\hline Preoperative right bundle branch block & 31 & $10(32)$ & 62 & $3(5)$ & $<.01$ \\
\hline Preoperative diuretics & 31 & $9(29)$ & 62 & $10(16)$ & .15 \\
\hline Preoperative maximal gradient $(\mathrm{mm} \mathrm{Hg})$ & 31 & $103 \pm 28$ & 62 & $120 \pm 48$ & .14 \\
\hline \multicolumn{6}{|l|}{ Echocardiographic data (preoperative) } \\
\hline $\operatorname{LVEF}(\%)$ & 31 & $70 \pm 5$ & 62 & $71 \pm 6$ & .56 \\
\hline LV basal septum $(\mathrm{mm})$ & 31 & $20 \pm 3$ & 62 & $20 \pm 5$ & .88 \\
\hline $\mathrm{LV}$ posterior wall $(\mathrm{mm})$ & 29 & $14 \pm 3$ & 62 & $13 \pm 2$ & .57 \\
\hline LV mass index $\left(\mathrm{g} / \mathrm{m}^{2}\right)$ & 29 & $156 \pm 41$ & 62 & $162 \pm 60$ & .79 \\
\hline Diastolic dysfunction (1-4) & 24 & $1.7 \pm 0.5$ & 43 & $1.9 \pm 0.6$ & .22 \\
\hline LVEDD (mm) & 31 & $47 \pm 6$ & 62 & $47 \pm 6$ & .96 \\
\hline $\operatorname{LVESD}(\mathrm{mm})$ & 27 & $27 \pm 6$ & 60 & $26 \pm 4$ & .83 \\
\hline LA diameter (mm) & 27 & $59 \pm 9$ & 60 & $62 \pm 8$ & .07 \\
\hline LAD volume index $\left(\mathrm{mL} / \mathrm{m}^{2}\right)$ & 30 & $53 \pm 16$ & 61 & $52 \pm 23$ & .39 \\
\hline RVSP & 23 & $40 \pm 17$ & 49 & $38 \pm 13$ & .93 \\
\hline
\end{tabular}

Data are expressed as n (\%) or mean \pm standard deviation. BMI, Body mass index; $C V A$, cerebrovascular accident; $C O P D$, chronic obstructive pulmonary disease; $N Y H A$, New York Heart Association; FAC, functional aerobic capacity; SD, sudden death; HCM, hypertrophic cardiomyopathy; ICD, implantable cardioverter defibrillator; NSVT, nonsustained ventricular tachycardia; $V T$, ventricular tachycardia; $M R I$, magnetic resonance imaging; $L V E F$, left ventricular ejection fraction; $L V$, left ventricle; $L V E D D$, left ventricular end-diastolic diameter; $L V E S D$, left ventricular end-systolic diameter; $L A$, left atrium; $L A D$, left atrial diameter; RVSP, right ventricular systolic pressure.

preoperative Holter study and a family history of sudden death (SD). In the primary myectomy group, the single patient who had an ICD discharge for VT 11 months after surgery had massive septal hypertrophy (35 $\mathrm{mm})$ and NSVT on preoperative Holter study and a family history of SD.

\section{Mitral Regurgitation}

All patients in both groups had some degree of mitral valve regurgitation that was dynamic and related to systolic anterior motion of the anterior leaflet; 23 of 31 patients $(74 \%)$ in the prior alcohol septal ablation group and 46 of 62 patients $(74 \%)$ in the myectomy group had moderate or more mitral regurgitation preoperatively. All patients with mitral regurgitation had significant improvement after appropriate relief of LVOT obstruction. Postoperatively, there was mild or no residual mitral regurgitation in both groups. No patient required direct mitral valve surgery, and none had more than mild postoperative mitral regurgitation at postoperative echocardiography.

\section{Histopathologic Analysis}

All samples were compared between patients with previous alcohol septal ablation and controls (Table 3). The 
TABLE 2. Comparison of perioperative in-hospital (myectomy) data

\begin{tabular}{|c|c|c|c|c|c|}
\hline \multirow[b]{2}{*}{ Variable } & \multicolumn{2}{|c|}{ Prior alcohol septal ablation } & \multicolumn{2}{|c|}{ Primary myectomy } & \multirow[b]{2}{*}{$P$ value } \\
\hline & $\mathbf{n}$ & Value & $\mathbf{n}$ & Value & \\
\hline Cardiopulmonary bypass time (min) & 31 & $37 \pm 20$ & 62 & $35 \pm 17$ & .93 \\
\hline Cardiac ischemic time (min) & 31 & $26 \pm 14$ & 62 & $26 \pm 15$ & .95 \\
\hline Postoperative LVEF & 31 & $62 \pm 9$ & 62 & $64 \pm 7$ & .31 \\
\hline Maximum gradient postoperatively & 31 & $4 \pm 7$ & 62 & $3 \pm 5$ & .94 \\
\hline LV basal septum (mm) postoperatively & 25 & $15 \pm 4$ & 52 & $15 \pm 4$ & .34 \\
\hline Myectomy (grams of tissue) & 31 & $4.6 \pm 2$ & 62 & $5.0 \pm 3$ & .63 \\
\hline RVSP postoperatively & 21 & $39 \pm 13$ & 42 & $36 \pm 10$ & .57 \\
\hline Postoperative ICD implanted & 31 & $5(16)$ & 62 & $7(11)$ & .51 \\
\hline Postoperative PPM implanted & 31 & $4(13)$ & 62 & $3(5)$ & .16 \\
\hline \multicolumn{6}{|l|}{ Complications } \\
\hline New complete AV block & 31 & $6(19.4)$ & 62 & $1(1.6)$ & $<.01$ \\
\hline Aortic valve injury & 31 & 0 & 62 & 0 & - \\
\hline New VSD & 31 & 0 & 62 & 0 & - \\
\hline Atrial fibrillation & 31 & $9(29)$ & 62 & $16(25)$ & .74 \\
\hline Low cardiac output & 31 & $2(6)$ & 62 & $1(1.5)$ & .21 \\
\hline Dialysis & 31 & $1(3)$ & 62 & 0 & .15 \\
\hline Mechanical ventilation time ( $>24 \mathrm{~h})$ & 31 & $3(10)$ & 62 & $2(3)$ & .19 \\
\hline Reexploration for bleeding & 31 & $1(3)$ & 62 & $2(3)$ & 1.00 \\
\hline Cerebrovascular accident & 31 & 0 & 62 & 0 & - \\
\hline
\end{tabular}

Data are expressed as n (\%) or mean \pm standard deviation. $L V E F$, Left ventricular ejection fraction; $L V$, left ventricle; $R V S P$, right ventricular systolic pressure; $I C D$, implantable cardiverter defibrillator; $P P M$, permanent pacemaker; $A V$, atrioventricular; $V S D$, ventricular septal defect.

degree of interstitial fibrosis in the specimens was significantly higher in the prior alcohol septal ablation group $(70 \%$ vs $26 \%$ with moderate or greater fibrosis, $P<.01)$. Likewise, patients with previous alcohol septal ablation had more endocardial fibrosis $(87 \%$ vs $67 \%$ with moderate or greater fibrosis, $P=.04)$. There were no differences in the degree of myocyte disarray or

TABLE 3. Comparison of histopathologic and echocardiographic (strain) findings

\begin{tabular}{|c|c|c|c|}
\hline Variable & $\begin{array}{l}\text { Primary } \\
\text { myectomy }\end{array}$ & $\begin{array}{c}\text { Prior alcohol } \\
\text { septal ablation }\end{array}$ & $\begin{array}{c}P \\
\text { value }\end{array}$ \\
\hline $\begin{array}{l}\text { Pathology (septal myectomy } \\
\text { specimen) }\end{array}$ & $\mathrm{n}=60$ & $\mathrm{n}=30$ & \\
\hline $\begin{array}{l}\text { Myocyte hypertrophy } \\
\text { moderate or more }\end{array}$ & $58(97)$ & $30(100)$ & .31 \\
\hline $\begin{array}{l}\text { Interstitial fibrosis } \\
\text { moderate or more }\end{array}$ & $16(27)$ & $21(70)$ & $<.01$ \\
\hline $\begin{array}{l}\text { Endocardial fibrosis } \\
\text { moderate or more }\end{array}$ & $40(67)$ & $26(87)$ & .04 \\
\hline $\begin{array}{l}\text { Myocyte disarray } \\
\text { moderate or more }\end{array}$ & $12(20)$ & $7(23)$ & .71 \\
\hline Weight (g) & $5.00 \pm 2.59$ & $4.63 \pm 1.93$ & .63 \\
\hline Strain analysis (preoperative) & $\mathrm{n}=55$ & $\mathrm{n}=24$ & \\
\hline Global S & $-14.39 \pm 3.00$ & $-13.95 \pm 3.48$ & .61 \\
\hline Global SR & $-0.83 \pm 0.17$ & $-0.78 \pm 0.18$ & .63 \\
\hline Global early diastolic SR & $0.77 \pm 0.18$ & $0.67 \pm 0.18$ & .03 \\
\hline Septal S & $-13.61 \pm 3.24$ & $-13.12 \pm 4.12$ & .61 \\
\hline Septal SR & $-0.77 \pm 0.19$ & $-0.72 \pm 0.23$ & .18 \\
\hline Septal early diastolic SR & $0.72 \pm 0.21$ & $0.58 \pm 0.19$ & $<.01$ \\
\hline
\end{tabular}

Data are expressed as $\mathrm{n}(\%)$ or mean \pm standard deviation. $S$, Strain; $S R$, strain rate. hypertrophy between the groups, $P=.71$ and $P=.31$, respectively. No amyloidosis or calcification was identified in this study. Inflammation was identified in 2 cases (1 case of mild, perivascular lymphocytic inflammation and 1 case with a single focus of granulomatous inflammation without identifiable microorganisms).

\section{Strain Analysis}

The global early diastolic strain rate differed significantly; in the prior alcohol septal ablation group mean strain rate was significantly greater than that in the primary myectomy group $(P=.03)$. In focused analysis of the septum, the early diastolic strain rate was also higher in the prior alcohol septal ablation group compared with the control group $(P<.01)$. Both findings indicate a greater degree of diastolic dysfunction in the presence of a prior alcohol septal ablation.

\section{Association Between Diastolic Dysfunction and Septal Fibrosis}

We categorized septal fibrosis at the endocardial and interstitial levels into 2 groups, none/mild or moderate/ severe, and then compared these grades of fibrosis with septal strain analysis. Although not statistically significant, patients with more advanced degrees of interstitial fibrosis had a trend toward worse diastolic function measured by strain (less than moderate, $-14.03 \% \pm$ $3.16 \%$; moderate or more, $-12.56 \% \pm 3.88 \%$, $P=.08)$. This tendency was not apparent with regard to 
endocardial fibrosis and diastolic dysfunction by strain evaluation (Table E1).

\section{DISCUSSION}

In the present study, the outcome of myectomy in patients who received prior alcohol septal ablation was worse than that of patients who received myectomy as initial septal reduction therapy. Patients with prior alcohol septal ablation experienced more postoperative complications, including a strikingly high incidence of complete atrioventricular block. Cardiac deaths, arrhythmias, and advanced heart failure symptoms at follow-up were higher in this group compared with patients undergoing myectomy as first therapy. From an anatomic-functional standpoint, echocardiographic and histopathologic analysis revealed a substrate fibrosis with resulting impairment of diastolic function, which may explain these clinical findings. This study is unique in the integration of anatomic, echocardiographic, and clinical findings to assess the outcome of myectomy for obstructive HCM.

Outcome data confirm that extended septal myectomy relieves LVOT obstruction regardless of whether the basal septum has been altered by prior alcohol septal ablation. Gradient relief was similar to that in our larger septal myectomy experience. ${ }^{4}$ Even with a limited number of patients, we found differences in freedom from cardiac death among groups.

In an attempt to understand differences in these populations, we focused on the underlying morphologic substrate present at the time of myectomy. Significantly more fibrosis, both interstitial and endocardial, was observed in specimens in the prior alcohol septal ablation group. Of note, the interstitial fibrosis noted in the prior alcohol septal ablation group was largely replacement-type fibrosis, presumably measured away from the region of infarction. Pericellular-type fibrosis was seen to a greater extent in the prior alcohol septal ablation cohort. Regions of myocardium adjacent to infarctions can exhibit pericellular-type fibrosis, and this may represent an adverse epiphenomenon of the infarction event. Of note, endocardial fibrotic thickening was seen to a greater degree in the alcohol septal ablation cohort and possibly due to residual obstruction. Our findings suggest that although the ethanol reaches the culprit region of obstruction, the depth of septal muscle after alcohol septal ablation is heterogeneous, leading to unpredictable and potentially suboptimal therapeutic effects.

Scarring and fibrosis demonstrated in myectomy specimens from patients having previous alcohol septal ablation represents a small portion of infarcted septum. With the use of magnetic resonance imaging, Valeti and colleagues ${ }^{23}$ studied 24 patients before and 3 to 7 days after alcohol septal ablation. The estimated mass of infarcted septum was $16 \mathrm{~g}$, and scar involved up to $30 \%$ of the septum; moreover, 6 patients had sparing of the basal septum with residual gradients at follow-up. Thus, the mechanism of septal reduction therapy in alcohol septal ablation differs from the discrete and directed excision produced during myectomy. Remarkably, histopathologic findings from specimens suggested that ethanol reached the culprit (obstructive) septum at the time of prior alcohol septal ablation but failed in relieving obstruction. The extent of septal fibrosis identified in patients with prior alcohol septal ablation is unknown because the surgical specimen was limited to the obstructing septum, but it is likely that this process is more diffuse and contributes to further heart damage.

To understand the functional impact of myocardial scarring beyond analysis of the histologic specimens, we analyzed echocardiographic images. Although we were not able to identify differences in preoperative conventional echocardiographic analysis, we retrospectively performed a strain analysis. The results of this analysis are consistent with increased diastolic dysfunction and loss of myocardial compliance that may be due to scarring after alcohol septal ablation. Indeed, a strong correlation was observed between more advanced degrees of interstitial fibrosis and worse diastolic function measured by strain at the septal level (septal strain, septal SR, septal early diastolic SR). These findings may explain the observation that although myectomy relieved LVOT gradients to a similar extent, patients with prior alcohol septal ablation exhibited more advanced degrees of heart failure at follow-up compared with matched patients who had only myectomy.

In addition to diastolic dysfunction, septal scar from alcohol septal ablation may contribute to rhythm abnormalities. In some reports, risk of complete heart block may reach $20 \%$ after alcohol septal ablation. ${ }^{18}$ In our patients, the incidence of preoperative complete heart block was higher in the alcohol septal ablation group, as well as the frequency of preoperative right bundle branch block. Septal myectomy commonly produces a left bundle branch block $(46 \%),{ }^{24}$ and thus preexisting right bundle branch block at the time of surgical myectomy may confer an increased risk of complete heart block and translates into an increased incidence of this complication in our prior alcohol septal ablation group.

Much is unknown regarding the risk of late arrhythmias and SD after alcohol septal ablation. Noseworthy and colleagues ${ }^{25}$ reported that the risk of malignant arrhythmias was $4.9 \%$ per year after alcohol septal ablation. ten Cate and colleagues ${ }^{26}$ found that after alcohol septal ablation, $7 \%$ of patients died suddenly and $12 \%$ survived 1 or more episodes of VT during late follow-up. In our cohort, 1 patient in the prior alcohol septal ablation group had SD after successful myectomy, and the postmortem examination seemed to corroborate the clinical diagnosis of an arrhythmic event. Our preoperative Holter data suggest differences between groups regarding the potential for late arrhythmias and SD; VT/NSVT was more prevalent in 
patients with previous alcohol septal ablation. It is important to note that patients having alcohol septal ablation before myectomy had increased use of ICDs for prevention of SD compared with the control group. Fibrosis in patients with HCM quantified by means of magnetic resonance imaging has been correlated with an increased risk of late arrhythmic events. ${ }^{27}$ In contrast to the outcome of patients having alcohol septal ablation, McLeod and colleagues ${ }^{28}$ reported a reduction in the risk of arrhythmias and SD after surgical septal myectomy. The impact of implanted devices on quality of life, inappropriate discharges, and their intrinsic complications are of major concern and still under investigation.

Little is known about the influence of fibrotic myocardial changes after alcohol septal ablation in terms of contractile performance, ${ }^{29}$ but our results suggest a correlation between the extent of fibrosis quantified histologically and the diastolic dysfunction measured by echocardiographic strain analysis. Myocardial infarction may lead to reduced ventricular compliance and diastolic impairment contributing to increased advanced heart failure at follow-up, as seen in our patients.

\section{Study Limitations}

Alcohol septal ablation is an alternative therapy for obstructive HCM involving the LVOT if the risk of septal myectomy is considered to be prohibitive. ${ }^{1,30}$ Our study is subject to the limitations inherent to a nonrandomized and retrospective analysis. In an effort to identify a comparison group, we used propensity matching from a large pool of patients who underwent septal myectomy at the Mayo Clinic. Variables used for the matching process were selected to balance baseline characteristics. Another limitation is the inability to clearly define the denominator of alcohol septal ablations performed and the rate of failure of this therapy due to the referral pattern of our patients. Although we have been able to demonstrate differences in several outcome variables between populations, this study is underpowered to detect differences in many comparisons because of a relatively small number of patients (31) with failed alcohol septal ablation requiring myectomy. Another limitation of this study is the relatively short average follow-up time.

\section{CONCLUSIONS}

Patients with prior alcohol septal ablation and residual LVOT obstruction undergoing rescue septal myectomy have an increased risk of death, advanced heart failure, and ICD discharges compared with patients undergoing septal myectomy as the primary septal reduction therapy. Our data contribute to accumulating evidence that the infarction induced by alcohol septal ablation may have adverse and unexpected consequences.

\section{Conflict of Interest Statement}

Authors have nothing to disclose with regard to commercial support.

The authors thank Zhuo Li for statistical analysis and Judy Lenoch for data retrieval

\section{References}

1. Gersh BJ, Maron BJ, Bonow RO, Dearani JA, Fifer MA, Link MS, et al. 2011 ACCF/AHA guideline for the diagnosis and treatment of hypertrophic cardiomyopathy: a report of the American College of Cardiology Foundation/American Heart Association Task Force on Practice Guidelines. J Thorac Cardiovasc Surg. 2011;142:e153-203.

2. Maron MS, Olivotto I, Zenovich AG, Link MS, Pandian NG, Kuvin JT, et al. Hypertrophic cardiomyopathy is predominantly a disease of left ventricular outflow tract obstruction. Circulation. 2006;114:2232-9.

3. Maron MS, Olivotto I, Betocchi S, Casey SA, Lesser JR, Losi MA, et al. Effect of left ventricular outflow tract obstruction on clinical outcome in hypertrophic cardiomyopathy. N Engl J Med. 2003;348:295-303.

4. Ommen SR, Maron BJ, Olivotto I, Maron MS, Cecchi F, Betocchi S, et al. Longterm effects of surgical septal myectomy on survival in patients with obstructive hypertrophic cardiomyopathy. J Am Coll Cardiol. 2005;46:470-6.

5. Williams LK, Rakowski H. Surgical myectomy for hypertrophic obstructive cardiomyopathy: the cut that heals. Circulation. 2013;128:193-7.

6. Maron BJ, Dearani JA, Ommen SR, Maron MS, Schaff HV, Gersh BJ, et al. The case for surgery in obstructive hypertrophic cardiomyopathy. J Am Coll Cardiol. 2004; 44:2044-53.

7. Nagueh SF, Ommen SR, Lakkis NM, Killip D, Zoghbi WA, Schaff HV, et al. Comparison of ethanol septal reduction therapy with surgical myectomy for the treatment of hypertrophic obstructive cardiomyopathy. J Am Coll Cardiol. 2001:38:1701-6.

8. Nagueh SF, Groves BM, Schwartz L, Smith KM, Wang A, Bach RG, et al. Alcohol septal ablation for the treatment of hypertrophic obstructive cardiomyopathy. A multicenter North American registry. J Am Coll Cardiol. 2011;58:2322-8.

9. Dearani JA. Septal myectomy remains the gold standard. Eur Heart J. 2012;33: 1999-2000.

10. Sorajja P, Ommen SR, Holmes DR, Dearani JA, Rihal CS, Gersh BJ, et al Survival after alcohol septal ablation for obstructive hypertrophic cardiomyopathy. Circulation. 2012;126:2374-80.

11. Maron BJ, Maron MS. Hypertrophic cardiomyopathy. Lancet. 2013;381:242-55.

12. Sorajja P, Binder J, Nishimura RA, Holmes DR Jr, Rihal CS, Gersh BJ, et al. Predictors of an optimal clinical outcome with alcohol septal ablation for obstructive hypertrophic cardiomyopathy. Catheter Cardiovasc Interv. 2013;81:E58-67.

13. ElBardissi AW, Dearani JA, Nishimura RA, Ommen SR, Stulak JM, Schaff HV Septal myectomy after previous septal artery ablation in hypertrophic cardiomyopathy. Mayo Clin Proc. 2007;82:1516-22.

14. Nagueh SF, Buergler JM, Quinones MA, Spencer WH III, Lawrie GM. Outcome of surgical myectomy after unsuccessful alcohol septal ablation for the treatment of patients with hypertrophic obstructive cardiomyopathy. J Am Coll Cardiol. 2007;50:795-8.

15. Maron BJ, McKenna WJ, Danielson GK, Kappenberger LJ, Kuhn HJ, Seidman CE, et al; Task Force on Clinical Expert Consensus Documents. American College of Cardiology; Committee for Practice Guidelines. European Society of Cardiology. American College of Cardiology/European Society of Cardiology Clinical Expert Consensus Document on Hypertrophic Cardiomyopathy. J Am Coll Cardiol. 2003;42:1687-713.

16. Schaff HV, Dearani JA, Ommen SR, Sorajja P, Nishimura RA. Expanding the indications for septal myectomy in patients with hypertrophic cardiomyopathy: results of operation in patients with latent obstruction. J Thorac Cardiovasc Surg. 2012;143:303-9.

17. Nishimura RA, Ommen SR. Hypertrophic cardiomyopathy: the search for obstruction. Circulation. 2006;114:2200-2.

18. Sorajja P, Valeti U, Nishimura RA, Ommen SR, Rihal CS, Gersh BJ, et al. Outcome of alcohol septal ablation for obstructive hypertrophic cardiomyopathy. Circulation. 2008;118:131-9.

19. Schaff HV, Said SM. Transaortic extended septal myectomy for hypertrophic cardiomyopathy. Oper Tech Thorac Cardiovasc Surg. 2012;17:238-50.

20. Ashikhmina EA, Schaff HV, Ommen SR, Dearani JA, Nishimura RA, Abel MD. Intraoperative direct measurement of left ventricular outflow tract gradients to 
guide surgical myectomy for hypertrophic cardiomyopathy. J Thorac Cardiovasc Surg. 2011;142:53-9.

21. Maron BJ, Wolfson JK, Roberts WC. Relation between extent of cardiac muscle cell disorganization and left ventricular wall thickness in hypertrophic cardiomyopathy. Am J Cardiol. 1992; 70:785-90.

22. Maron BJ, Spirito P, Shen WK, Haas TS, Formisano F, Link MS, et al. Implantable cardioverter-defibrillators and prevention of sudden cardiac death in hypertrophic cardiomyopathy. JAMA. 2007;298:405-12.

23. Valeti US, Nishimura RA, Holmes DR, Araoz PA, Glockner JF, Breen JF, et al. Comparison of surgical septal myectomy and alcohol septal ablation with cardiac magnetic resonance imaging in patients with hypertrophic obstructive cardiomyopathy. J Am Coll Cardiol. 2007;49:350-7.

24. Talreja DR, Nishimura RA, Edwards WD, Valeti US, Ommen SR, Tajik AJ, et al. Alcohol septal ablation versus surgical septal myectomy: comparison of effects on atrioventricular conduction tissue. J Am Coll Cardiol. 2004;44:2329-32.

25. Noseworthy PA, Rosenberg MA, Fifer MA, Palacios IF, Lowry PA, Ruskin JN, et al. Ventricular arrhythmia following alcohol septal ablation for obstructive hypertrophic cardiomyopathy. Am J Cardiol. 2009;104:128-32.

26. ten Cate FJ, Soliman OI, Michels M, Theuns DA, de Jong PL, Geleijnse ML, et al. Long-term outcome of alcohol septal ablation in patients with obstructive hypertrophic cardiomyopathy: a word of caution. Circ Heart Fail. 2010;3: 362-9.
27. Appelbaum E, Maron BJ, Adabag S, Hauser TH, Lesser JR, Haas TS, et al Intermediate-signal-intensity late gadolinium enhancement predicts ventricula tachyarrhythmias in patients with hypertrophic cardiomyopathy. Circ Cardiovasc Imaging. 2012;5:78-85.

28. McLeod CJ, Ommen SR, Ackerman MJ, Weivoda PL, Shen WK, Dearani JA et al. Surgical septal myectomy decreases the risk for appropriate implantable cardioverter defibrillator discharge in obstructive hypertrophic cardiomyopathy. Eur Heart J. 2007;28:2583-8.

29. Flores-Ramirez R, Lakkis NM, Middleton KJ, Killip D, Spencer WH III, Nagueh SF. Echocardiographic insights into the mechanisms of relief of left ventricular outflow tract obstruction after nonsurgical septal reduction therapy in patients with hypertrophic obstructive cardiomyopathy. J Am Coll Cardiol. 2001;37:208-14.

30. Maron BJ, Maron MS, Wigle ED, Braunwald E. The 50-year history, controversy, and clinical implications of left ventricular outflow tract obstruction in hypertrophic cardiomyopathy from idiopathic hypertrophic subaortic stenosis to hypertrophic cardiomyopathy: from idiopathic hypertrophic subaortic stenosis to hypertrophic cardiomyopathy. J Am Coll Cardiol. 2009;54:191-200.

Key Words: Hypertrophic obstructive cardiomyopathy, septal alcohol ablation, septal myectomy

\title{
EDITORIAL COMMENTARY
}

\section{The law of the instrument}

\author{
Richard Lee, MD, MBA
}

See related article on pages 159-67.

I suppose it is tempting, if the only tool you have is a hammer, to treat everything as if it were a nail. -Abraham H. Maslow ${ }^{1}$

In preparing for this editorial commentary on the article in this issue of the Journal by Quintana and colleagues, ${ }^{2}$ I searched the Internet, using the senior author and myectomy as keywords. I was led to a YouTube video, which I, as had more than 10,000 others before me, viewed intensely. ${ }^{3}$ In it, Dr Schaff discussed the disease and options, with an

\footnotetext{
From the Department of Surgery, Saint Louis University, Center for Comprehensive Cardiovascular Care, St Louis, Mo.

Disclosures: Author has nothing to disclose with regard to commercial support.

Received for publication May 3, 2015; accepted for publication May 5, 2015.

Address for reprints: Richard Lee, MD, MBA, Saint Louis University, Center for Comprehensive Cardiovascular Care, 3635 Vista Ave, St Louis, MO 63110 (E-mail: rlee@slu.edu).

J Thorac Cardiovasc Surg 2015;150:167-8

$0022-5223 / \$ 36.00$

Copyright (C) 2015 by The American Association for Thoracic Surgery

http://dx.doi.org/10.1016/j.jtcvs.2015.05.019
}

emphasis on surgery. In it, he reports a surgical experience of more than 1500 myectomies at the Mayo Clinic, including more than 50 with the apical approach alone. Most surgeons do not perform 50 Morrow procedures in an entire career. There is no doubt that Dr Schaff is not only one of the world's leading experts on

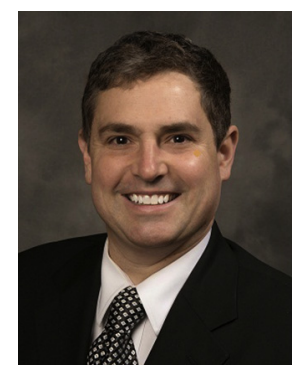
this disease but is already and will forever be a historic figure. Anyone who has ever met him knows that no one deserves it more.

That said, while reading this article, which demonstrates that surgical outcomes are worse after failed septal ablation, it struck me that all of us, particularly surgeons, are subject to Abraham Kaplan's Law of the Instrument, which can be formulated as "Give a small boy a hammer, and he will find that everything he encounters needs pounding." The concept likely first originated as an English expression calling a hammer a Birmingham screwdriver, referencing the practice of using one tool for all purposes. Our bias as surgeons is that we want to see surgery as better, even if we don't admit this to ourselves.

In this article, Quintana and colleagues ${ }^{2}$ compared 31 patients undergoing myectomy after septal ablation with 
TABLE E1. Comparison between echocardiographic and histopathologic analysis of the interventricular septum

\begin{tabular}{|c|c|c|c|c|c|c|}
\hline & \multicolumn{3}{|c|}{ Interstitial fibrosis } & \multicolumn{3}{|c|}{ Endocardial fibrosis } \\
\hline & Less than moderate & Moderate or more & $P$ value & Less than moderate & Moderate or more & $P$ value \\
\hline Septal S & $-14.03 \pm 3.16$ & $-12.56 \pm 3.88$ & .08 & $-14.12 \pm 3.32$ & $-13.19 \pm 3.58$ & .29 \\
\hline Septal SR & $-0.78 \pm 0.20$ & $-0.71 \pm 0.21$ & .08 & $-0.78 \pm 0.17$ & $-0.74 \pm 0.22$ & .24 \\
\hline Septal early diastolic SR & $0.72 \pm 0.23$ & $0.63 \pm 0.19$ & .07 & $0.70 \pm 0.20$ & $0.67 \pm 0.22$ & .60 \\
\hline
\end{tabular}

